Narodna biblioteka Srbije, Beograd

DOI 10.5937/kultura1133161B

UDK 141.319.8:316.72"20"

003.3:316.774

TRANSFORMACIJE KONCEPATA USMENOSTI IPISMENOSTIU INFORMATCKKOJ KULTURI

Sažetak: Osnovni problemski okvir predloženog rada određen je uočavanjem krupnih promena u odnosu između usmenosti i pismenosti u savremenom informatičkom društvu i ogromnog transformacionog upliva koji te promene imaju u globalizujućim društvenim pokretima. Relaciju usmenost/pismenost tretiramo kao aktuelno i živo pitanje današnjeg sveta, moderne nauke i savremenog mišljenja. Usmenost $i$ pismenost shvatamo u širem smislu kao kompleksne pojave, književno-jezičke $i$ kulturne, naročito u savremenom dobu u kojem jezik, komunikacija i informacija dobijaju presudni značaj u društvenoj dinamici. Važno je istaći da se ne uspostavlja oštra granica među usmenim i pisanim tekstovima, već se oni razlikuju samo po stepenu svoje usmenosti/literarnosti. Naime, ako je ova tema nekada bila predmet proučavanja pre svega književnosti, lingvistike i folkloristike, ona danas postaje glavno područje interesovanja i antropologije, kulturologije, filozofije, sociologije, teorije medija, psihologije, ekonomije i politikologije, te se može označiti i prepoznati kao paradigmatski okvir savremenog humanističkog mišljenja, kao deo "linguistic turna" izvedenog u humanističkim i društvenim naukama od šezdesetih godina XX veka. Opozicija usmenog i pismenog interferira s nizom drugih pojmovnih opozicija: anonimno/kolektivno - individualno; tradicionalno - moderno; ruralno - urbano; masovno - elitno; popularno/pučko - učeno; narodno umetničko/veštačko; zvukovno - vizuelno. S druge strane, i sâm odnos prema jeziku se menja. Tako, npr., intertekst u elektronskoj komunikaciji funkcioniše kao nov oblik usmenosti. Granice između usmenosti $i$ pismenosti se sve više brišu.

Ključne reči: govor, usmenost, pismenost, informatička kultura, komunikacija, globalizacija 
Kroz celokupnu ljudsku povest čovečanstvo je određeno nekim medijem. U današnjem svetu sveprisutnih mas-medija pomalo je zaboravljeno ono medijsko posredovanje svojstveno vremenima oralnosti, pojave pisma i štampe. U svom radu koncentrisaćemo se na elemente posredovanja kao što su govor, jezik i pismo.

Predmet ovog rada, (koji je zamišljen kao okosnica jedne buduće šire studije), čini analiza sudbine usmenosti i pismenosti u savremenoj informatičkoj kulturi. Osnovni problemski okvir određen je posmatranjem usmenosti i pismenosti kroz vizuru dijahronijski datih komunikacionih tehnologija (govor, pismo, štampa, elektronski zapis) čime dolazimo do neophodnog instrumentarijuma za razumevanje savremene globalne kulture, u njenoj međuzavisnosti s novim tehnologijama komunikacije.

Usmenost i pismenost shvaćene su ovde kao kompleksne pojave, književno-jezičke i kulturne, naročito u savremenom dobu u kojem jezik, komunikacija i informacija imaju presudan značaj u društvenim kretanjima. Važno je istaći da se ne uspostavlja oštra granica među usmenim i pisanim tekstovima, već se oni razlikuju samo po stepenu svoje usmenosti/literarnosti. Stoga je pristup našoj temi neminovno interdisciplinaran. Ova tema je u prošlosti bila predmet proučavanja pre svega književnosti, folkloristike i lingvistike, a danas postaje glavno područje interesovanja i antropologije, filozofije, sociologije, kulturologije, psihologije, ekonomije, komunikologije, teorije medija, politikologije.

Pritom pojmovna opozicija usmenog i pisanog diskursa (u raspravi o tekstovima), odnosno usmenog i pismenog izražavanja (agrafičkog i grafičkog u raspravi o vrstama društava u kojima tekstovi nastaju i žive) - interferira s nizom drugih pojmovnih opozicija: anonimno/kolektivno - individualno; tradicionalno - moderno; ruralno - urbano; masovno - elitno; popularno (pučko) - učeno; narodno - umetničko (veštačko); zvukovno - vizuelno.

Tema koju razmatramo, odnosno sam odnos usmenosti i pismenosti, deo je šireg problema međuodnosa nefiksirane i fiksirane forme čovekove stvaralačke delatnosti. Razume se, usmenost nije vezana samo za nefiksirane, a pismenost za fiksirane forme čovekovog stvaralaštva, naročito gledano iz antropološke perspektive. Ovaj problem se ne iskazuje samo u saodnosu usmenosti i pisanosti u narodnoj i uopšte književnosti, nego i u muzici, pozorištu, plesu, arhitekturi itd. Radi se o dijalogu dvaju osnovnih formi postojanja kulture i njenog prenošenja kroz generacije. 


\section{JADRANKA BOŽIĆ}

\section{Uvod}

U prvom, uvodnom, delu rada dat je prikaz konceptualnih određenja usmenosti i pismenosti, s naglaskom na proširenom konceptu pismenosti, zatim razgraničavanje usmene i pisane književnosti i žanrova. Sledi istorija postavljanja problema odnosa usmenost/pismenost (pet glavnih etapa istorije problema), pregled tri osnovna dijahronijski data lingvistička gledišta o odnosu između govora i pisma $i$, na kraju, razmatranje pojma informatičke kulture.

Pojam primarne pismenosti podrazumeva jedan oblik komunikacije koju pismena svest teško može da zamisli, jer je naše celokupno iskustvo pismoliko. Za koncept usmenosti najbitniji je neposredan (usmeni) način komuniciranja, za razliku od posrednosti pisanog komuniciranja (pismenosti).

Pismenost je mnogo više od sposobnosti čitanja i pisanja. Sâma ta sposobnost podrazumeva i podstiče niz drugih umeća i veština, pa se otuda mora govoriti o različitim kognitivnim, psihološkim, sociološkim i drugim implikacijama pismenosti. Pismenost je jedna istinska vežba uma, jedna potpuno nova tehnologija intelekta. Pored razvijanja logičkog mišljenja, pisanjem se na viši stepen podižu umeće introspekcije i čovekova samosvest. Nasuprot anonimnosti oralne tradicije, čovek se pisanjem individualizuje.

Tradicionalna i elementarna pismenost je očigledno nedovoljna za uspešan i kvalitetan život u savremenom društvu informacija i znanja. Novi, prošireni koncept pismenosti obuhvata skup veština kakve su kompjuterska pismenost, medijska, digitalna i informatička pismenost. Informatička pismenost podrazumeva proces doživotnog učenja i uspešnog prilagođavanja dinamičkom okruženju informacionih tehnologija.

Zbog izrazite upućenosti stvaralaca na auditorijum, usmenu književnost definišemo kao osobenu kontaktnu umetničku komunikaciju, svojevrstan događaj u kontekstu. Za sagledavanje složenosti nastanka i prihvatanja usmenih dela, bitna su još tri činioca: tekst (o tekstu usmene varijante može se govoriti tek pošto je umotvorina zabeležena; zapis usmenog dela je tek segment njegovog postojanja); tekstura (pod teksturom se u folklorističkim istraživanjima podrazumevaju: naglasak, intonacija, interpretacija glasom, napevom, mimikom i kretanjem); i kontekst (aktivna upućenost usmenog stvaraoca na publiku, okolnosti u kojima delo nastaje).

Za kvalifikaciju dela kao usmenog (narodnog, folklornog) nije bitna njegova geneza, poreklo i izvor sižea i motiva, već način njegovog funkcionisanja - usmeno, neposredno. Osim samog 
usmenog funkcionisanja, usmenu književnost obeležavaju i njene vanknjiževne funkcije, koje se ne iscrpljuju samim širim područjem umetnosti (muzika, ples), nego pripadaju i praktičnom životu,

kao deo obreda i svečanosti, kao magija itd.

U okviru ovog dela rada predstavljamo i istorijat postavljanja problema odnosa usmenost/pismenost, preliminarni prikaz koji se oslanja u velikoj meri na zaključke Vladimira Bitija izložene u tekstu Upisivanje govornog događaja u okviru zbornika Usmeno $i$ pisano/pismeno u književnosti $i$ kulturi, koji je priredio Svetozar Petrović.

Prvu apologiju usmenosti predstavlja Platonovo, veoma uticajno, odbacivanje pisma zbog otuđivanja izvornih obeležja govora. Paradoksalno, bez učinaka koje je pismo imalo na strukturu umnih procesa, Platonova filozofska misao se uopšte ne bi mogla pojaviti, a i ovaj napad na pismo je iznet u pisanom obliku. Platon koristi dugotrajnu linearnu analizu za koju ljudi usmene kulture nisu sposobni. Tekstualizacija svesti je i rodila jezičku apstrakciju stvari.

U drugoj apologiji usmenosti reč je o prelazu s renesansne na klasicističku epistemu. Naime, dok renesansa ustoličuje pisanu reč kao medij istine, klasicizam pretvara govorni jezik u medij predstavljanja ideje.

Treću etapu obeležava Frojd. Svest čoveka XVIII veka je već podrazumevala tekstualizaciju. Niko nije potpunije od Frojda teorijski razradio postavku o tekstualnom ustrojstvu svesti. Na gramatičku stranu teksta, Frojd je stavio sposobnost svesti da zapamti sve ikad primljene nadražaje, a na psihološku njenu sposobnost da se, kao očišćena, otvori novim nadražajima. Da bi jezik mogao imati nekakvu ulogu u artikulaciji jedinica spoznajnog univerzuma, pre no što se pojavi kao naknadno sredstvo njihovog prenošenja - to je uvid koji se razgovetno javlja tek s Ničeom i Frojdom. Oni nedvosmisleno pokazuju da su pojmovi kojima raspolaže ljudska svest nastali procesima kanalizacije jezičke prakse.

Četvrtu etapu ćemo postaviti na početak XX veka i obeležiti ga imenima fenomenologa Huserla i strukturalista Sosira i Levi Strosa. Kao što Sosir ne podnosi pismo u lingvistici, Levi Stros smatra da je ono jedan od uzročnika i pratilac svega negativnog u civilizaciji. Videti u pismu samo jednu stranu, samo instrument eksploatacije čoveka u istoriji, jednostrano je jer zanemaruje njegovo drugo, emancipatorsko lice.

Deridina teza da razlika/pomak/odgoda obeležava početak čovekove percepcije drugosti - može se proglasiti pragom nove, pete i ujedno završne etape istorijata postavljanja problema 


\section{JADRANKA BOŽIĆ}

odnosa usmenost/pismenost. U svojoj knjizi $O$ gramatologiji Derida iznosi argumente protiv fonocentrizma koji privileguje govor $\mathrm{u}$ odnosu na pisanje.

Napravićemo distinkciju između govora (usmeni govor) i pisanja, pisma (pismeni ili pisani govor). Govor je realizacija jezika. Jezik i govor stoje u odnosu kôda i poruke, sistema i procesa; govor je jezik u akciji. Jezik se može ostvarivati različitim sredstvima. Realizacija jezika u zvučnim talasima je govorenje, a u grafičkoj masi - pisanje.

Daćemo kratak osvrt na istorijski promenljiva lingvistička gledišta o odnosu između govora i pisma, odnosno govornog i pisanog jezika, kao medija u stvaranju, prenosu i recepciji jezika (tri osnovne teorijske pozicije). Naime, u najranijem periodu filologije, pisanju je davan primat nad govorom. S razvojem fonetike i dijalektologije krajem XIX veka jezik je izjednačen s govorom, dok je pisanje praktično isključeno iz lingvistike. Sredinom XX veka, naročito pod uticajem Praške lingvističke škole, govor i pisanje sagledavaju se kao dva delimično autonomna, komplementarna i jednako vredna lingvistička medija ili kôda, i ovaj stav je najšire prihvaćen i u današnjoj nauci.

Jezik, odnosno govorni jezik, primarno je biološki, pa onda i kulturni fenomen, dok pismo, odnosno, pisani jezik nema izvornu biološku podlogu i u celosti pripada sferi kulture. Čovek govori otkad postoji, bar 100.000 godina, dok piše tek nekih 5.000 godina.

Pod informatičkom kulturom podrazumevamo već ustaljene navike i praksu pojedinaca i celokupnog društva u korišćenju širokog spektra informacija, s posebnim osloncem na kompjuterskoj i telekomunikacionoj tehnologiji. Globalna kompjuterizacija, odnosno informatizacija kulture, opšte su mesto i trenutno stanje stvari u svetu, sa svojim specifičnim konsekvencama, imperativima i okolnostima.

\section{Usmeno/pismeno}

Osnovna teza ovog rada je da promene u tehnologijama komunikacije nikada nisu samo tehnološke inovacije; važno je naglasiti da nova, kompjuterska tehnologija ne podrazumeva samo tehnički usavršena sredstva - ona utiče na promene u načinu razmišljanja, što dovodi do preobražaja osećajnosti i inteligencije i šire, utiče na promene u socijalnoj i ekonomskoj organizaciji društva. Prelaženje iz usmenosti u pismenost, kao i iz jedne pismenosti u drugu (npr. informatičku) nije samo tehnički korak, nego i prelomna tačka u obrascima učenja i saznanja. 
Strahovit procvat informatičke industrije $u$ devedesetim godinama XX veka i prvoj deceniji XXI veka postavlja temelj za stvaranje informatičkog društva, koje će, potpuno je jasno, biti dominantan model društvenog organizovanja u III milenijumu. Iz te činjenice proističe i promena čovekovog mentalnog sklopa i njegove duhovnosti, koji se saobražavaju i prilagođavaju tehnologiji.

Do sada su bile u upotrebi četiri osnovne komunikacione tehnologije: oralna (govor), pismo, štampa i elektronski zapis. Svaki od ovih medija (tehnoloških sredstava) ima svoje karakteristike, ali nijedan nije prekinut ni danas, samo je zauzeo specifično mesto i rang u modernoj kulturi.

Otkriće superiornog grčkog alfabeta od 24 slova u VIII veku p.n.e., smatra se prelomnim događajem u stvaranju moderne kulture. Pronalazak pismenosti, koji se pokazao kao presudan za promenu prirode grčke svesti, imao je istu ulogu u čitavoj Evropi i u stvari se može smatrati odgovornim za oblikovanje karaktera moderne consciousness u svetskim razmerama. Erih Havelok je u svojoj studiji Muza uči da piše: razmišljanja o usmenosti i pismenosti od drevnosti do danas pokušao da odgovori na pitanje da li je sâmo logičko mišljenje proizvod grčke alfabetske pismenosti. U okviru svoje Posebne teorije grčke pismenosti Havelok ukazuje na činjenicu da se Platonova i uopšte grčka filozofska misao ne bi mogla pojaviti bez učinaka koje je pismo imalo na strukturu umnih procesa. I Valter Ong se u svom radu Writting is a Technology that Restructures Thought poziva na Havelokove uvide koji pokazuju da je, isto tako, ukupna filozofska kritika mitskog nasleđa bila nezamisliva bez prestrojavanja diskurzivne formacije grčkog jezika, tokom koje su se, kao rezultat dugotrajnog sažimanja mitova, oblikovali prvi apstraktni pojmovi. Naime, svođenje različitih diskursa na zajednički apstraktni imenilac bilo je povezano s prestrukturacijom grčkog uma pod uticajem alfabeta. Grčka metafizika odnela je istorijsku pobedu nad mitom tek pošto joj je pisani um, združujući svoje percepte u obuhvatnije sklopove, omogućio identifikaciju njihovog zajedničkog jezgra i tek pošto su, zahvaljujući tome, reči počele služiti imenovanju stvari umesto naznačavanju sklopa njihovog funkcionisanja. Isto tako, tekstualizacija svesti rodila je jezičku apstrakciju stvari i time ih uvela $u$ distinktivno postojanje.

Evo kako usmeni i pismeni diskurs oslikava Peter Sloterdajk: $Z a$ razliku od alfabetske koja je kadra da se distancira, prealfabetska inteligencija se kreće u klimi koncentrisanijeg učestvovanja pošto je za njen razvoj, budući da je smeštena isključivo u blizinsku komunikaciju, potrebno da iskusi komunizam prisutnih mozgova i nerava. U eri čitanja, taj će se komunizam pretvoriti 


\section{JADRANKA BOŽIĆ}

u kvazi-telepatsku republiku učenjaka koja s razlogom ima svoje vlastite duhove vremena; zahvaljujući pismu, sada pažnju mogu dodatno da okupiraju i duhovi davnih vremena. Osim toga, pismo omogućava da se pojedinci povuku iz društva kako bi se upotpunili glasovima pisaca - onaj ko ume da čita, taj ume $i$ da bude sam. Tek alfabetizacija omogućava anahorezu:

knjiga i pustinja idu zajedno...

Tek je pismo razorilo začarani krug usmenosti i tek je zahvaljujući njemu čitalac emancipovan od totalitarizma aktuelne, u blizini izgovorene reči; pisanje i čitanje, naročito kada se upotrebljavalo na grčki, demokratski, autodidatski način, dobra je vežba za stanje ne-zanetosti. Usmeno doba je doba magijske manipulacije tokom praistorije duše: u njemu je normalan slučaj bila trenutna opsednutost glasom i sugestijama drugih pripadnika plemena. Zaposednutost normalnim, prosečnim, prisutnim, naravno da ne pada u oči: sve do danas se u porodicama, selima, gradskim četvrtima, smatra da je to jednostavan, direktan, samorazumljiv tip komunikacije. Pritom se zataškava da su u usmenom svetu svi ljudi čarobnjaci koji jedni na druge bacaju manje ili više moćne čini normalizovanja. ${ }^{1}$

Kriza komunikacije koja se dogodila u staroj Grčkoj kada je usmenost zamenjena pismenošću, a zatim i kriza u XV veku kada se s rukopisne kulture prelazilo na štampu, može se uporediti sa sličnom krizom u moderno doba, kada se tradicionalna pismenost suočava sa informatičkom pismenošću. Dovodeći ih u vezu, pokušaćemo da jednom krizom osvetlimo drugu.

Usmenost treba shvatiti u nešto širem smislu od očite razlike između napisanog i samo izgovorenog teksta, otprilike onako kako je shvata Erik Havelok, kada opisuje najveću revoluciju evropske kulture, prelaz sa usmene kulture na kulturu koja se služi pismom. Bitna osobina usmene komunikacije, naime, nije samo govor umesto pisma, nego je takođe i poseban tip govora koji se može i zapisati - uzmimo kao primer poruke na mobilnim telefonima.

U svom tekstu Retorika i mitologija postmoderne Milivoj Solar, kao osnovne karakteristike postmoderne kulture, ističe prevlast usmenosti nad pismenošću u savremenoj komunikaciji, slike nad pojmom, sinhronije nad dijahronijom. Usmena komunikacija ne poznaje razradu određene teme, osim u formulaičnim oblicima takozvane usmene književnosti. Svodi se na fluidnost zapažanja, najčešće je razumljiva jedino iz stvarnog konteksta, podaci koje

1 Sloterdajk P., Sfere, mehurovi, u: Beogradski književni časopis 12, Beograd 2008 , str. 119. 
iznosi načelno su neprovjerljivi, a temeljni joj se oblici ne mogu svesti na književne žanrove. Nalik su nevezanom čavrljanju, a kada se služe nekim dužim oblikom - nazvaću to tipom diskurza - onda se najčešće oblikuju poput mita, bajke ili trača. Televizijske vijesti najbolji su primer teškoća oko provjerljivosti podataka; premda su podrijetlom usmeni oblici, mit, bajka i trač lako se mogu prepoznati u zapisanom obliku, a takvim se uvelike koriste novine i časopisi. Ne mislim time da je na pomolu nova epohalna revolucija u komunikaciji, kakvu je recimo McLuhan najavljivao, no smatram da se prevlast takve, šire shvaćene usmenosti može razabrati kako u svakidašnjem životu tako i u danas dominirajućim književnim oblicima. ${ }^{2}$

Centralni deo rada tematizuje probleme opšteg društvenog ubrzanja, globalnosti, multimedijalnosti, interaktivnosti, hiperteksta, nelinearne, rizomatske, organizacije mišljenja, transverzalnosti, kiper-prostora $\mathrm{i}$ interneta, promene razumevanja odnosa između fikcionalnog i stvarnog - pristupajući ovim pojmovima kao osnovnim parametrima za razumevanje savremene globalne kulture u njenoj međuzavisnosti s novim tehnologijama komunikacije. Multimedijalni oblik mišljenja favorizuje prostornost u odnosu na vreme, menja predstavu o celovitosti sveta i iskustva, otvara nove mogućnosti za preferiranje fragmentarnog i multiplikovanog iskustva.

\section{Nelinearno mišljenje i koncept hiperteksta}

Nova informatička pismenost ponovo je uvela bogatije, nelinearne oblike komunikacije. Svedoci smo velikih promena sâmog odnosa prema jeziku, granice između usmenosti i pismenosti su sve fluidnije. Tako, na primer, intertekst u elektronskoj komunikaciji funkcioniše kao nov oblik usmenosti. Kompjuterski roman je interaktivan jer omogućuje čitaocu da učestvuje u njegovom oblikovanju prema vlastitim zamislima (u čemu razabiramo usmenu svest). Književnost se tako na neki način vraća drevnom pripovedanju i usmenom predanju. Usmena književnost je po nekim svojim karakteristikama hipertekst. Transverzalnost podrazumeva maksimalnu rasprostranjenost i prisutnost komunikacije na različitim ravnima i u različitim pravcima. Digitalni hipertekst je samo jedna od pojava kojom se na delu pokazuje novi model shvatanja sveta.

Hipertekst je medij nelinearne organizacije informacionih jedinica. Iako se danas, kada se govori o hipertekstu, misli na digitalno proizvedeni tekst, preteče, artefakti hiperteksta, nalaze se već u

2 Solar M., Retorika i mitologija postmoderne, u: Glasnik Odjeljenja društvenih nauka, Crnogorska akademija nauka i umetnosti 20, Podgorica 2010, str. 129. 
pojmovima otvorenog umetničkog dela (Umberto Eko), ali i u delima Kafke, Prusta, Malarmea, Klajsta; Sternov Tristram Šendi, Džojsovo Fineganovo bdenje ili Deridin Glas su hipertekstovi. Zar i Biblija nije jedan pra-hipertekst?

Prethodna ontologija bila je modelirana po slici korena ili konceptu drveta. Razmišljalo se unutar jedne predstave o poreklu, o prvoj osnovi. Drvo, kao koncept, visoko je organizovana i trajna struktura, ima istoriju. Roman XIX veka je drvo; on ima početak, sredinu, kraj i linearni tok.

Ontologija zasnovana na rizomskoj predstavi, međutim, razmišlja o prostoru heterogeniteta i koneksija. Rizom postaje pogled na svet; on povezuje bilo koju tačku s bilo kojom drugom tačkom. Nasuprot centralizovanim sistemima, rizom je nehijerarhizovan, definisan jedino kruženjem stanja (Delez, Gatari). Berouzov roman Goli ručak je, na primer, rizom - može se čitati s bilo koje strane, nema celinu, već samo sklop. Rizom podrazumeva sklapanje i preplitanje bezbroj ravni, splet filozofije, seksa, fudbala, psihoanalize, mode i bilo čega drugog. I sve se dešava sada taj sklop nema ni istoriju ni poreklo.

Teorijska razmišljanja o tekstu u doba postmoderne bila su odana ideji o proizvođenju jednog beskonačnog teksta: pisanje izobličenjima, navodima, suplementacijama, samoreferencijama. Kad Derida kaže da je svako pisanje beskonačno, on još uvek slavi svetkovinu pisanja. Skliznuće od pojma mikro-hiperteksta koji ima u vidu Derida, ka pojmu makro-hiperteksta koji se ima u vidu kad je reč o tekstovima $u$ mreži - bilo je neprimetno. Bilo je potrebno promeniti kôd i primeniti tehniku.

Događa se prelaz od još-uvek-knjiga ka ne-više-knjiga, s linearnog na nesekvencijalno, nelinearno pisanje, izlazak iz Gutenbergove galaksije i ulazak u Turing Galaxy - sa ideje klasične knjige na opendesk kompjutera.

S jedne monadičke predstave o svetu ide se ka nomadskoj. Stoga i koncept pisanja nije više insularan, već transverzalan. Transverzalnost podrazumeva maksimalnu rasprostranjenost i prisutnost komunikacije na različitim ravnima i u različitim pravcima - novi vodeći model predstave o svetu. Digitalni hipertekst je samo jedna od pojava kojom se na delu pokazuje novi model shvatanja sveta.

Hiperfikcija je elektronički hipertekst koji tekst razumeva kao tkanje, teksturu, ima rizomsku strukturu: otvorenost, metafora za hiljadu ravni, antisistem, pačvork, apsolutno rasejanje. Nelinearnost i transverzalnost su jedna vrsta sistema mišljenja. Jedan hipertekst je u stvari i sâm jedna fusnota, naime, svoja sopstvena fusnota. Hipertekst tako unutar tehničkog medija 
ostvaruje san Barta, Eka, Deleza i Deride o intertekstualnosti i nomadskom mišljenju.

Ontološki koncept hiperteksta baziran je na pojmu i konceptu interteksta. Sâm, pak, intertekst je fenomen koji se može razmatrati iz perspektive nauke o književnosti, semiotike, dekonstruktivističke filozofije i psihoanalize. Termin je u praksu izučavanja književnosti uvela Julija Kristeva. Intertekstualnost je apsorpcija i transformacija jednog teksta u drugom.

Intertekstualnost (proširena u interkulturalnost), kao temeljni pojam mišljenja, nadasve pogodan da bude integrisan $u$ arsenal sredstava nomadizma, jeste suštinsko obeležje savremenog kreiranja književnog teksta i, takođe, poetičkih i estetičkih promišljanja. O nomadskoj atitudi, dakle o lutanju, duhovnoj peregrinaciji možemo govoriti i kao svetonazorskom stavu

koji dotiče sve diskurse.

\section{Nove dimenzije oprostoravanja}

Odnos između prostora i vremena prošao je kroz dramatične promene zbog inovacija u komunikacionim tehnologijama. Teoretičari to ovako opisuju: Žan Bodrijar govori o imploziji ôsa vreme/prostor; Entoni Gidens kaže da su koordinate vreme/ prostor kolabirale; Pol Virilio smatra da živimo u vremenu bez kašnjenja; Manuel Kastels piše da je razliveni prostor zamenio mesni prostor.

Kategorija istine jeste ozbiljno problematizovana u savremenom svetu i to ima veze s postojećim tehnologijama komunikacije. U prilog ovoj tezi navešću pregled stanovišta nekoliko autora (Imanuela Kanta, Valtera Benjamina, Žana Bodrijara, Divne Vuksanović).

Starogrčko shvatanje prostora i vremena, u funkciji objektivnih predikata koji konstituišu referentni okvir stvarnosti, izmenjeno je kantovskim preobražajem estetskih saznanja prostora i vremena kao sferâ čiste subjektivnosti i apriorne opažajnosti. Ovaj obrt imaće dalekosežne posledice po savremeno shvatanje receptiviteta i pojavnosti kao takve. Nagoveštaj ovog radikalnog obrta nalazimo kod Benjamina u njegovom Saznajno-kritičkom predgovoru za studiju Poreklo nemačke žalobne igre. Naime, on smatra da fenomeni pojavnog i iskustvenog znanja odnose prevagu nad metafizičkim svetom stvari i suština.

Postmoderna je internacionalna kultura svojstvena postindustrijskom, informatičkom i semiotičkom društvu. Postmoderno prihvatanje površnosti i razgradnja objektivnih vrednosti i merila ostavlja društvo bez celine vrednosti. Na filozofskom i epistemološkom planu postmodernizam obuhvata poricanje svakog 


\section{JADRANKA BOŽIĆ}

utvrđenog značenja, realnosti, istine ili činjenica. (Na jezgrovitu kritiku ovakvog preteranog relativizma nalazimo u Oksfordskom filozofskom rečniku Sajmona Blekburna.)

Po Bodrijarovom mišljenju, savremeni razvijeni svet postao je jedan opšti interaktivni performans, u kojem se realnost gubi i zamenjuje hiperrealnošću ili simulacijom stvarnog života: nestaje razlika između bića i privida. Živimo u vremenu u kojem slike nekog događaja zamenjuju neposredno iskustvo; imitacija

postaje stvarnost, simulacija zamenjuje istinu.

Divna Vuksanović, na liniji mnogih savremenih mislilaca, krajnje radikalizuje ovaj sled misli smatrajući da se savremena era komunikacija poklapa s gubitkom pojma, pa time i instance istine i implozijom smisla modernog sveta, čime estetski fenomeni poput prostora i vremena dobijaju na epistemološkom i kulturološkom značaju.

Internet, pod kojim se često podrazumeva i pojam kiber-univerzuma, za mnoge korisnike i teoretičare predstavlja novi svet slobodnih asocijacija, otvorene i permanentne komunikacije. Prema nekim teoretičarima, internet je uprkos svojoj apsolutnoj otvorenosti - zapravo privatni domen, produžetak individualne svesti i subjektivnih afiniteta. Prema drugima, internet je javni prostor. Kategorija virtuelnog implicira tezu da je internet univerzum koji postoji nezavisno od konvencija realnosti, pružajući iluziju anonimnosti. Međutim, privatnost komunikacije na internetu je samo delimična. Prema nekim mišljenjima, jedna od najdubljih konsekvenci prelaženja u informatičko i elektronsko doba je izbleđivanje privatnog jastva (self). Menja se predstava o tome šta znači biti čovek, ličnost, polako nestaje subjektivni prostor; pomalja se nova kolektivizacija - na neki način povratak usmenosti. Na liniji takvih razmišljanja je i Divna Vuksanović, koja svet interneta percipira kao svet kolektivno nesvesnog, u kojem se ne nazire naše svesno, već nesvesno $\mathrm{u}$ arhetipskom domenu. Ona deli mišljenje onih teoretičara za koje su novi mediji, kao izazov i atrakcija novog doba, zapravo pretnja subjektivitetu.

Ukoliko hermeneutika jeste tumačenje okrenuto prema tekstu, ne može se zamisliti neka teorija tumačenja koja bi zaobilazila problem pisanja.

U daljim istraživanjima, govoreći o novim dimenzijama oprostoravanja, ne bi se smela zaobići Rikerova analiza odnosa temporalnosti i narativnosti, kao ni odnos Bahtina i Lotmana prema prostoru i vremenu kao osnovnim kategorijama analize umetničkih dela (Bahtinov hronotop, Lotmanov akcenat na doživljaju i predstavljanju prostora). 
Već smo konstatovali da multimedijalno mišljenje favorizuje prostornost u odnosu na vreme. Zahvaljujući mas-medijima veze između ovde i drugde postaju vidljivije nego one između pre i posle. Današnji svet prepoznaje sebe više kao mrežu koja spaja tačke i preseca linije, nego kao život koji se ispoljava kroz vreme. Oprostoravanje je Deridin termin koja označava prostornost koja se dešava; prostornost obuhvata i preobražavanje vremena u prostor.

\section{Karakteristike globalne komunikacije $i$ globalizacija kulture}

Završni deo rada posvećen je odnosima novih komunikacionih tehnologija i karakteristika savremene globalno-medijsko-kibernetske kulture i društva. Stvaranjem mogućnosti transkontinentalnih, odnosno satelitskih prenosa, informaciono-komunikaciona sredstva (mediji) pretvorili su Zemljin šar u Makluanovo globalno selo. Globalizacija se tiče politike, tehnologije i kulture, baš kao i ekonomije. Na nju je iznad svega uticao nagli razvoj komunikacionih tehnologija, započet krajem šezdesetih godina XX veka.

U savremenoj antropologiji kultura je shvaćena kao prostor komunikacija. Globalna ekumena, globalna kulturna komunikacija je prostor neprekidnih uzajamnih delovanja i kulturne razmene.

U svetu koji se globalizuje, u kojem se informacije i slike rutinski prenose širom planete, svi smo u stalnom kontaktu $\mathrm{s}$ drugima koji razmišljaju na drugačiji način i žive drugačije od nas (globalna komunikacija). Trenutna elektronska komunikacija ne predstavlja samo način da se vesti ili informacije prenose na brži način. Njeno postojanje menja sâmo tkanje naših života, i to iz temelja. Globalizacija (mondijalizacija) na svakodnevni život utiče isto onoliko koliko i na događaje na svetskom nivou.

Globalizacija se može definisati kao intenzifikacija društvenih odnosa na svetskom planu, koja povezuje udaljena mesta na takav način da lokalna zbivanja uobličavaju događaji koji su se odigrali kilometrima daleko $\mathrm{i}$ vice versa.

$* * *$

Treba istaći da je i pored svih preovlađujućih elektronskih transformisanja klasičnih sadržaja u savremenoj civilizaciji, slušanja i gledanja prevashodno, usmeno pripovedanje ostalo neprolazni predmet pomnog interesovanja i u savremenim okvirima, trajna estetska kategorija. U današnjim književnostima, pojava, na primer, sve većeg broja afričkih, 
aboridžinskih australijskih ili indijanskih pisaca - govori o usmenoj strukturi pripovedanja koja je samo preuzela znakovni sistem pisanog jezika, a i dalje pripovedanje ima svoj nekadašnji smisao zvučanja, odjeka i doziva: iako napisana, knjiga se još uvek prenosi i usmeno.

\section{LITERATURA:}

Bošković Stulli M., Usmena književnost, u: Povijest hrvatske književnosti, Zagreb 1978.

Božić J., Analogni i digitalni mediji: čovek i njegov identitet u informatičkoj kulturi, u: Glasnik Narodne biblioteke Srbije, 1, Beograd, 2007, str. 121-132.

Božić J., U znaku Perseja i Ikara: knjiga u elektronskoj civilizaciji, u: Kultura, 101, Beograd 2001, str. 165-174.

Bugarski R., Pismo, Beograd 1997.

Clifford J.i Marcus G., Writting Culture: The Poetics and Politics of Ethnography, Berkley and Los Angeles 1986.

Dagognet P., Ecriture et iconographie, Paris 1973.

Diringer D., The Alphabet: A Key to the History of Mankind, I-II, New York 1968.

Eriksen T. H., Tiranija trenutka, Beograd 2003.

Eror G., Genetički vidovi (inter)literarnosti, Beograd 2002.

Gilster P., Digital Literacy, New York 1997.

Goody J. i Watt J., The Consequences of Literacy, in: Literacy in Traditional Societies, eds. Goody J., Cambridge, str. 27-68.

Goody J., Entre l'oralité et l'ecriture, Paris 1994.

Havelok E., Muza uči da piše: razmišljanja o usmenosti i pismenosti od drevnosti do danas, Novi Sad 1991.

Hil M. V., Uticaj informacije na društvo, Beograd 2008.

Kelner D., Medijska kultura, Beograd 2004.

Lecours A. R., The Origins and Evolution of Writting, in: Origins of the Human Brain, Cambridge 1993.

Lord A., Pevač priča, I-II, Beograd 1990.

Lozica I. i Perić Polonijo T., Pisani dijalog o usmenosti, u: Narodno stvaralaštvo - folklor, sv. 1-4, Zagreb 1986.

Mangel A., Istorija čitanja, Novi Sad 2005.

Maticki M., Ponovnice: tipovi odnosa usmene i pisane književnosti, Novi Sad 1989.

O usmenoj književnoj tradiciji (temat), u: Zbornik Matice srpske za književnost, 48, Novi Sad 2000. 
Ong W., Writting Is a Technology that Restructures Thought, in: The Written Word: Literacy in Transition, eds. Baumann G., Oxford 1986.

Pelc M., Pismo - knjiga - slika: uvod u povijest informacijske kulture, Zagreb 2002.

Petrović S., O prevladavanju granice među proučavanjem usmene i proučavanjem pisane književnosti, u: Letopis Matice srpske, dec., Novi Sad 1975, str. 1007-1020.

Petrović S., ur., Usmeno i pisano/pismeno u književnosti i kulturi, Beograd 1988.

Queneau R., Préeminence de l'oral sur l'écrit, u: Panorama des idées contemporaines, red. Picon G., Paris 1957, str. 397-399.

Riker P., Pisanje kao problem za književnu kritiku i filozofsku hermeneutiku, u: Reč, 50, Beograd 1998, str. 107-117.

Samardžija S., Uvod u usmenu književnost, Beograd 2007.

Sloterdajk P., Sfere, mehurovi, u: Beogradski književni časopis, 12, Beograd 2008, str. 117-121.

Solar M., Retorika i mitologija postmoderne, u: Glasnik Odjeljenja društvenih nauka, Crnogorska akademija nauka i umjetnosti, 20, Podgorica 2010, str. 127-137.

Sretenović D., Stari i novi mediji, u: Manovič L., Metamediji, Beograd 2001, str. 136-145.

Tomašević B., Hiljadu ravni: transverzalni um, nelinearno pisanje, književni hipertekst i kraj Gutenbergove galaksije, u: Polja, 441, Novi Sad 2006, str. 48-56.

Ugričić S., Kultura i čovek dematerijalizacije, u: Glasnik Narodne biblioteke Srbije, br. 1, Beograd 2007, str. 147-151.

Vuksanović D., Filozofija medija, Beograd 2007. 
JADRANKA BOŽIĆ

\author{
Jadranka Božić \\ National Library of Serbia, Belgrade
}

\title{
TRANSFORMATION OF ORALITY AND LITERACY IN INFORMATION CULTURE
}

\begin{abstract}
The main problem in the proposed work is determined by the detection of major changes in the relationship between orality and literacy in the modern information society and the enormous influence of the transformation these changes brought about in the globalizing social movements. Relation orality/literacy is treated as a current and lively question of today's world, modern science and modern thought. By orality and literacy in a broader sense we understand such complex phenomena literary and linguistic, and cultural, especially in modern times when language, communication and information obtained decisive importance in social dynamics. It is important not to establish a sharp boundary between oral and written texts, for they differ only in their degree of oral / literariness aspects. Approach to this issue is in the interdisciplinary emphasis. In fact, this topic once a subject of study primarily of literature, linguistics and folklore is becoming now a major area of interest of anthropology, culturology, philosophy, sociology, media theory, psychology, economics and political science. The opposition of oral and written interferes with a number of other conceptual oppositions: anonymous/collective - individual, traditional - modern, rural - urban, mass - elite, popular/folk - scholarly, popular - artistic/ artificial; sound - visually. The topic you are considering, or the relation of orality and literacy as part of a problem is the relationship of unfixed and fixed forms of human creative activity. Of course, orality is not only related to the unfixed and fixed forms of literacy. It is the very relationship of language change. For example, in electronic communication intertext works are a new form of orality. The boundaries between orality and literacy are increasingly deleted. New computer literacy re-introduced a richer, nonlinear forms of communication. Computer novel allows the reader to participate in its formation (in which consciousness is perceived oral). Literature has also returned to the ancient storytelling and oral tradition. The oral literature is by some of its features a hypertext.
\end{abstract}

Key words: Speech, orality, literacy, information culture, communication, globalization 